\title{
Dendritic Cells, Viruses, and the Development of Atopic Disease
}

\author{
Jonathan S. Tam and Mitchell H. Grayson \\ Section of Allergy and Immunology, Department of Pediatrics, MACC Fund Research Center, \\ Medical College of Wisconsin, Room 5064, 8701 Watertown Plank Road, Milwaukee, WI 53226, USA \\ Correspondence should be addressed to Mitchell H. Grayson, mgrayson@mcw.edu
}

Received 14 June 2012; Accepted 17 September 2012

Academic Editor: Brian Oliver

Copyright ( 92012 J. S. Tam and M. H. Grayson. This is an open access article distributed under the Creative Commons Attribution License, which permits unrestricted use, distribution, and reproduction in any medium, provided the original work is properly cited.

\begin{abstract}
Dendritic cells are important residents of the lung environment. They have been associated with asthma and other inflammatory diseases of the airways. In addition to their antigen-presenting functions, dendritic cells have the ability to modulate the lung environment to promote atopic disease. While it has long been known that respiratory viral infections associate with the development and exacerbation of atopic diseases, the exact mechanisms have been unclear. Recent studies have begun to show the critical importance of the dendritic cell in this process. This paper focuses on these data demonstrating how different populations of dendritic cells are capable of bridging the adaptive and innate immune systems, ultimately leading to the translation of viral illness into atopic disease.
\end{abstract}

\section{Introduction}

Asthma and atopic diseases continue to increase in prevalence in westernized countries [1]; however, the cause for this rise remains unknown. While many hypotheses have been proposed, research continues into the mechanism(s) that drive the development of atopic disease. One potential hypothesis that has been proposed is that viral infections drive the development of atopy and atopic disease [2]. This may be somewhat counterintuitive, as antiviral immune responses are primarily interferon mediated and viewed as a prototypical $\mathrm{T}_{\mathrm{H}} 1$ immune response. Nonetheless, it is well documented that viral infections can aggravate asthma and induce development of asthma and atopic disease, that is, classic $\mathrm{T}_{\mathrm{H}} 2$ diseases. Dendritic cells (DCs), with their unique position bridging the adaptive and innate immune systems, are key resident immune cells in the interplay between viral infections and atopic disease. DCs are crucial to the initiation of the adaptive immune response and are uniquely able to condition Th differentiation. This paper focuses on data supporting a connection between viruses, IgE, and atopy and the critical importance of resident lung dendritic cells in translating a viral illness into atopic disease.

\section{Viruses, IgE, and Atopy}

Shortly after the discovery of IgE, it was noted that acute viral infections could drive IgE production-both virus specific and nonspecific [3-6]. Although a correlation was noted, the mechanistic reason for this increase (or for the role of $\operatorname{IgE}$ in viral illnesses, for that matter) remained unknown. Nonetheless, the association of IgE elevation and the similarity of symptoms between a viral upper respiratory tract infection and allergic rhinitis led some investigators to suggest a possible causative link between viral infections and atopic disease. The first study to hint at this was published in 1979, when Frick et al. [7] studied 13 children from atopic families to see if and when they developed atopic disease. In this small study, 11 of the children were noted to have upper respiratory tract infections in the 1 to 2 months prior to initial development of allergic sensitization. Because of this association, the authors hypothesized that viral infections might precipitate 
the development of atopic disease. Several other investigators have also documented associations in humans and mice between viral-induced IgE and atopic disease $[2,8,9]$.

Probably the strongest associations connecting viral infections to atopic disease have been found in studies looking at the development and exacerbation of asthma [10]. The virus most often associated with atopic disease is respiratory syncytial virus (RSV), a single-stranded RNA paramyxovirus that is a major pathogen in the Northern Hemisphere in the midwinter months and infects nearly all children by 2 years of age $[11,12]$. While most children get this infection early in life, a subset of infants (primarily in the 2- to 6month age range) who become infected with RSV develop a severe bronchiolitis requiring hospitalization. Sigurs et al. [13] showed that after viral infection these individuals were left with an increased risk for developing asthma (odds ratio $[\mathrm{OR}], 12.7)$, as well as allergic sensitization (OR, 2.4). The risk remained present through at least 13 years of age [14]. More recently, Wu et al. reported that a large unselected retrospective cohort of children born 4 months prior to the peak of RSV season had both the greatest risk of hospitalization for lower respiratory tract illness and the greatest risk of asthma between 4 and 5 years of age [15]. This study again supports the idea that a severe RSV infection requiring hospitalzation is associated with the development of atopy.

It has been suggested that the risk of atopy is not from the viral infection but instead is a result of an immune alteration that allows for reduced antiviral immunity [16]. In fact, some investigators have shown that individuals with atopic disease have reduced production of IFN- $\alpha$ from a subset of their dendritic cells, which may predispose them to a weaker antiviral immune response [17-19].

If the risk of atopic disease was not imparted by the viral infection, then reducing the severity of the infection with an anti-viral would be expected to have no effect on the subsequent development of atopy. Interestingly, the use of a monoclonal antibody directed against an epitope in the A antigenic site of the F protein of RSV (palivizumab) as prophylaxis against RSV in preterm infants, significantly increased the time to the first episode of recurrent wheeze and physician-diagnosed recurrent wheeze (hazard ratio $(H R)=0.46)[20]$. Furthermore, in a study of 175 patients who had acute RSV in which some received ribavirin and some did not, the rates of physician-diagnosed wheezing were decreased, as was the rate of allergic sensitization in the group that received the antiviral medication [21]. Together, these studies suggest that the prevention or early treatment of viral infections may be able to prevent subsequent development of asthma and atopic disease.

It is important to note that not all studies have shown a risk of RSV infection and atopy. For example, the Tucson Children's Respiratory Study includes more than 800 children with documented RSV infection in infancy. However, unlike the study by Stein et al., these infections were not severe enough to require hospitalization [22]. These children have been followed longitudinally for the development of asthma and other atopic diseases. And while RSV infection was shown to increase the risk of wheezing early in life, it was a transient risk, disappearing between 10 and 13 years of age.

Another virus associated with atopic disease is human rhinovirus (hRV), a nonenveloped, single-stranded RNA virus of the family Picornaviridae. On the basis of the sheer number of viral exposures, $\mathrm{hRV}$ is an important pathogen in the development of acute bronchiolitis in infants. In contrast to the seasonal nature of RSV, hRV infections occur throughout the year and are the main cause of bronchiolitis leading to hospitalization in infants outside of the winter months [23]. Children hospitalized with hRV tend to be older than those infected with RSV and are more likely to have a prior history of wheezing. These children often have more atopic risk factors, eczema, allergic sensitization, and parental asthma than do the RSV children [24, 25]. This difference, however, may simply relate to the ages of the infected children rather than to a specific effect of the virus. Similar to RSV, Kotaniemi-Syrjänen et al. [26] reported that children that were hospitalized with wheezing from $\mathrm{hRV}$ during the first 2 years of life were at increased risk of childhood asthma (OR 4.14) when compared to children hospitalized for wheezing with other viruses. Furthermore, in a Tennessee cohort of 90,000 children, an increased risk of asthma was found in children with episodes of bronchiolitis during nonwinter months [27]. Additionally, those with bronchiolitis during a month associated with higher rhinovirus exposure had a $25 \%$ greater risk of developing childhood asthma than those who developed infections during months where RSV was the primary cause of bronchiolitis [27].

Two birth cohort studies have identified outpatient hRV wheezing illnesses as important predictors of childhood asthma development as well. The Childhood Origins of Asthma (COAST) study examined a high-risk (1 parent with asthma or allergy) birth cohort of suburban children [28]. This study showed that a symptomatic hRV infection was the most important risk factor for development of wheeze by age 3 [29] and asthma by age $6(\mathrm{OR}, 25.6)$ [30]. The association of wheezing with prior hRV infection was stronger than that with RSV or any other viral pathogen. The COAST study involved a multivariate analysis that attempted to correct for other factors, such as pets, older siblings, participation in day care, breastfeeding, atopic dermatitis, and the presence of food-specific IgE. Further analysis of cytokine profiles in this cohort suggested that children with impaired Th1 responses (decreased release of interferon- $\gamma$ (IFN- $\gamma$ ) from cord blood monocytes) had increased numbers of viral infections in the first year of life [31]. However, it is not clear what role IFN- $\gamma$ (i.e., type II IFN) plays in the development of atopic disease (as opposed to IFN- $\alpha$ ).

In a similar high-risk birth cohort in Australia, Kusel et al. examined the risk of wheezing at 5 years of age in 198 patients who were at high risk of developing asthma [32]. These patients were enrolled as infants, monitored for respiratory infections, and had periodic checks for the development of asthma and atopy. At 5 years of age, the patients with current wheeze and asthma had a history of higher rates of respiratory infections with hRV or RSV. This association between viral infection and asthma was limited to the subgroup of patients who had developed allergic sensitization before 2 
years of age suggesting a role between early-life viral infection and development of allergic sensitization. Indeed, we have previously proposed that the ability of viruses to drive an atopic risk is limited to the first couple of years of life, after which viruses are more prone to exacerbate existing disease rather than lead to the development of new atopy [33].

As in studies of RSV and asthma, there is conflicting data concerning the causal role of viral infection and atopy. Recent statistical modeling of data from the COAST cohort claims that sensitization to aeroallergen primarily precedes any RVassociated wheezing [25], arguing against viral infection being causative in subsequent aeroallergen sensitization. It should be noted that the statistical model used for this study assumed continuous monitoring of both wheezing and sensitization. However, the cohort was only continuously monitored for wheezing and monitored annually for sensitization to aeroallergens. Consequently, while this study supports the findings from the Australian cohort, it does not fully refute the possibility that viral infection could be causative in initial allergic sensitization [34]. The mechanism(s) that might be responsible for translating these viral infections into atopic disease have only recently begun to be elucidated. It is interesting that in a mouse model there is a critical role for anti-viral IgE in the translation of the viral immune response into atopic disease, and this route is dependent upon the function of specific resident dendritic cells in the airway $[2,78]$.

\section{The Role for the Resident Dendritic Cell}

Dendritic cells (DCs) represent an important class of resident lung cells that are involved in initiating the immune response. While the nomenclature differs slightly between mouse and human, the knowledge and understanding gained from mouse DCs has led to better understanding in the human. In the mouse, DCs have been divided into two broad subtypes-conventional dendritic cells (cDCs) and plasmacytoid dendritic cells (pDCs). The cDCs are the major antigen-presenting cells in the body, whereas pDCs are major producers of the cytokine interferon- $\alpha$ (IFN- $\alpha$; type 1 IFN) and to a lesser extent IL12 $[35,36]$ and have been shown to play an important role in modulating immune responses as opposed to initiating them [37-42]. The cDCs express high levels of the integrin CD11c, whereas the pDCs express Siglec-H, Ly6C, and B220, but low levels of CD11c. However, there is some confusion in the literature over identification of $\mathrm{CDC}$, since other cell types can express CD11c. Recently, the zinc finger transcription factor Zbtb46 was shown to be specifically expressed in human and mouse cDCs $[43,44]$. In the future, this marker will likely be used to specifically identify these cells. Conventional DCs can be further subdivided based on expression of the integrins CD103 and CD11b. cDCs expressing CD103 (CD103 ${ }^{+}$ $\mathrm{CD}_{11 \mathrm{~b}^{-}}$), the $\alpha \mathrm{E}$ integrin, are resident cells found at mucosal sites under homeostatic conditions and are associated with the respiratory epithelium. These cells project their dendritic extensions between epithelial cells, allowing them to directly sample content of the airway lumen, and have been termed the "intraepithelial" subset [45]. CD11b expressing cDC

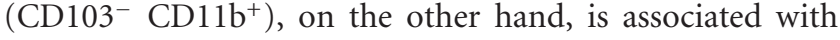
inflammatory stimuli and is found in the respiratory tract during ongoing activation of the immune response [46-48].

In humans, dendritic cells have also been divided into two broad subtypes-myeloid dendritic cells (mDCs-the equivalent of mouse cDCs: $\mathrm{CD} 11 \mathrm{c}+\mathrm{CD} 11 \mathrm{~b}+\mathrm{Gr} 1-\mathrm{B} 220-$ ) and pDCs (CD11c+CD11b-Gr1+B220+) [49]. Lung DCs in humans have been harder to characterize due to a lack of validated markers and the difficulty in obtaining human lung tissues for investigation; however, as mentioned, the novel transcription factor Zbtb46 is a robust marker of human cDC and will likely help clean up the identification of human DC subsets in the future $[43,44]$.

Dendritic cells are found throughout the lung and the entire respiratory tract epithelium, including the nose, nasopharynx, large conducting airways, bronchi, bronchioles, and alveolar interstitium $[45,50,51]$. These cells form an intricate cellular network just below the epithelial cell layer $[52,53]$. Their location and number underlie their function as sentinels and primary responders to potential pathogens. It has been estimated that there are between 400 and 800 resident dendritic cells per $\mathrm{mm}^{2}$ of epithelial surface in the rat airway [54]. In the absence of antigen, airway cDCs rapidly turnover, with an estimated $85 \%$ of the cell population changing every $36-48 \mathrm{~h}$; antigen exposure greatly increases this emigration. In the rat, it is estimated that the half-life of lung dendritic cells ranged from 1.5-2 days in the airway to 3-4 days in the periphery of the lung - both of which are much less than the 9 days or more in skin $[55,56]$.

Classically, cDCs ingest foreign proteins primarily through attachment of pattern recognition receptors, such as immunoglobulin $(\mathrm{FcR})$, carbohydrate (mannose receptor), complement (CR3), and toll-like receptors (TLRs). Once bound and ingested by pinocytosis, the proteins begin to break down in the endolysosome. These peptides then merge with a major histocompatibility complex (MHC) class II containing vesicle. This allows the peptides to bind to the MHC class II molecules and be exported to the surface, where they are presented to $\mathrm{T}$ cells. However, most antiviral immune responses are CD8 dependent and require presentation of antigen in the context of MHC class I. While some viruses can directly infect dendritic cells (e.g., herpes simplex virus, vaccinia virus, and measles virus) leading to presentation in MHC class I molecules, most do not appear to directly infect the dendritic cell [57-60]. To take up virus without being directly infected and yet express in it terms of MHC class I, the dendritic cell can express virus-binding receptors. For example, human immunodeficiency virus, cytomegalovirus, Ebola virus, dengue virus, and hepatitis $\mathrm{C}$ virus are all capable of binding to a C-type lectin, a specific intercellular adhesion molecule nonintegrin on DCs known as DC-SIGN [61]. Since many viruses do not have known receptors and cannot directly infect dendritic cells, the cell must also ingest virally infected cells (and virus) from the extracellular environment to obtain viral proteins to process. Then, through a process known as cross-presentation, the $\mathrm{cDC}$ is able to place the viral peptides in the context of MHC class I (rather than just MHC class II) [62]. 
It appears that cross-presentation (i.e., expressing extracellular peptides in the context of MHC class I) is a regular occurrence in DCs, even in the absence of an inflammatory insult. In fact, in this situation, it often initiates toleranceespecially if it occurs in the absence of dendritic cell activation $[63,64]$. However, in viral infections, the inflammatory response rapidly leads to activation of cDCs, and the cross-presentation pathway leads to a productive immune response. In the case of influenza or parainfluenza, it has been shown that pulmonary DCs rapidly become activated and migrate to the draining lymph node $[65,66]$. Within 6 hours of exposure to the virus, the draining lymph nodes contain numerous activated and mature pulmonary DCs. Interestingly, this DC response in the lymph node seems limited to the first inflammatory antigen encountered in the lung [65].

Plasmacytoid DCs are thought to play a major role in the antiviral immune response through production of IFN$\alpha$ and are rapidly recruited to the airway during respiratory tract viral infections $[66,67]$. The airway normally contains a much lower frequency of pDCs, although the numbers of pDCs may be influenced by genetic factors [68]. In a mouse model of viral respiratory infection, few pDCs are noted within the lung parenchyma at baseline, but with viral inoculation pDCs are rapidly recruited from the bone marrow and, within several days, comprise a majority of DCs in the virally infected lung $[66,69]$. Through production of IFN- $\alpha$, the pDCs are capable of skewing the immune system toward a predominantly Th1 antiviral immune response. Conversely, in a recent study by Pritchard et al., it was shown that depletion of $\mathrm{pDC}$ from RV-stimulated peripheral blood mononuclear cell (PBMC) cultures led to markedly inhibited IFN- $\alpha$ secretion and to a significant increase in expression and skewing toward production of Th2 cytokines [70].

In short, while the $\mathrm{pDC}$ population is responding directly to the lung insult, the cDCs that have ingested the invading organism are maturing in the draining lymph node and presenting antigen to $\mathrm{T}$ cells.

\section{Putting It All Together}

Despite the fact that most inhaled antigens are transported to the lymph nodes by lung-derived DCs, the usual outcome following the inhalation of harmless protein antigen is the induction of tolerance. Sakamoto et al. [71] infected mice with enough influenza virus to cause pneumonia; the mice were subsequently sensitized to aerosolized ovalbumin (OVA) associated with aluminum hydroxide adjuvant following the infection. Influenza infection prior to allergen sensitization resulted in elevated OVA-specific IgE levelsprovided that the OVA exposure occurred during the acute infection on days 2-6 after inoculation (p.i.). Exposure to OVA 14 days p.i. failed to enhance allergic sensitization. Further studies confirmed these observations with additional allergen challenge 3-4 weeks after primary sensitization [72, 73]. Moreover, Yamamoto et al. [73] reported a transient increase in airway DCs from day 2 to day 5 of influenza infection. In mice sensitized to OVA aerosol at the time of infection, the increase in DC number persisted for up to 5 weeks and was associated with high MHC class II expression by these cells. The authors concluded that recruitment of DCs to the airways during influenza infection may have contributed to enhanced sensitization to aeroallergens. Similar, to influenza, mice infected with RSV which were exposed to non-viral antigens (ragweed and OVA) with or without alum adjuvant from day 4 to day 8 p.i. were found to produce greater levels of allergen-specific antibodies in serum ( $\operatorname{IgE}$ and $\operatorname{IgG}$ ) and bronchoalveolar lavage (BAL) fluid (IgA and $\operatorname{IgG})$ than mice that were not infected with the virus $[74,75]$.

Sendai virus $(\mathrm{SeV})$, the murine parainfluenza virus type 1 , is a paramyxovirus and natural rodent pathogen. In a strain-dependent fashion, mice which survive a severe $\mathrm{SeV}$ infection develop chronic airway hyperreactivity and IL-13dependent mucous cell metaplasia, similar to human infants infected with RSV [76]. We have shown that this translation of viral to atopic disease requires an INF- $\alpha$-dependent accumulation of $\mathrm{CD} 49 \mathrm{~d}^{+}$polymorphonuclear neutrophils in the lung, which in turn induces resident lung $\mathrm{cDC}$ to express the high-affinity receptor for IgE (FceRI) [77]. Expression of FceRI on lung cDCs and the subsequent production of anti-SeV IgE were required for the development of postviral atopic disease [78]. In fact, we and others were able to show that crosslinking FceRI on the lung cDC led to production of CCL28 and subsequent recruitment of IL-13 producing Th2 cells in an antigen nonspecific fashion [78, 79].

Further, we have shown that a single exposure to a nonviral antigen (OVA) during an active anti-viral immune response is sufficient to drive significant and marked $\operatorname{IgE}$ production against the non-viral antigen [2]. Unlike previous reports with RSV or influenza, the development of OVA-specific IgE during an $\mathrm{SeV}$ infection did not require the use of an adjuvant. A subsequent challenge with the antigen alone led to augmented airway hyperreactivity and mucous cell metaplasia, demonstrating the development of atopic disease, as a result of a severe respiratory viral infection.

While these initial observations were made in mice, we have documented that the cDC FceRI-CCL28 axis appears operative in humans [80]. Further, it has been shown that expression of FceRI on human peripheral blood $\mathrm{CDC}$ is increased by respiratory viral infection [9]. However, unlike in the mouse, human cDCs appear to express FceRI from birth, although the regulation of its expression does appear to be quite complex with low levels of IgE having less of an effect on FceRI levels compared to higher IgE concentrations [81]. Therefore, while not completely validated in the human, critical portions of the cDC FceRI-CCL28 pathway appear intact in both mouse and man and begin to provide us with one mechanistic explanation for the translation of viral into atopic disease.

The process of inhalational tolerance is also influenced by pDCs, and there are good studies to suggest that these cells also play a role in the development of postviral atopic disease. In mice in which pDCs were depleted, RSV infection led to greater disease with increased viral titers and airway inflammation, as well as postviral airway hyperresponsiveness [69, 82]. This outcome is consistent with the need for effective 


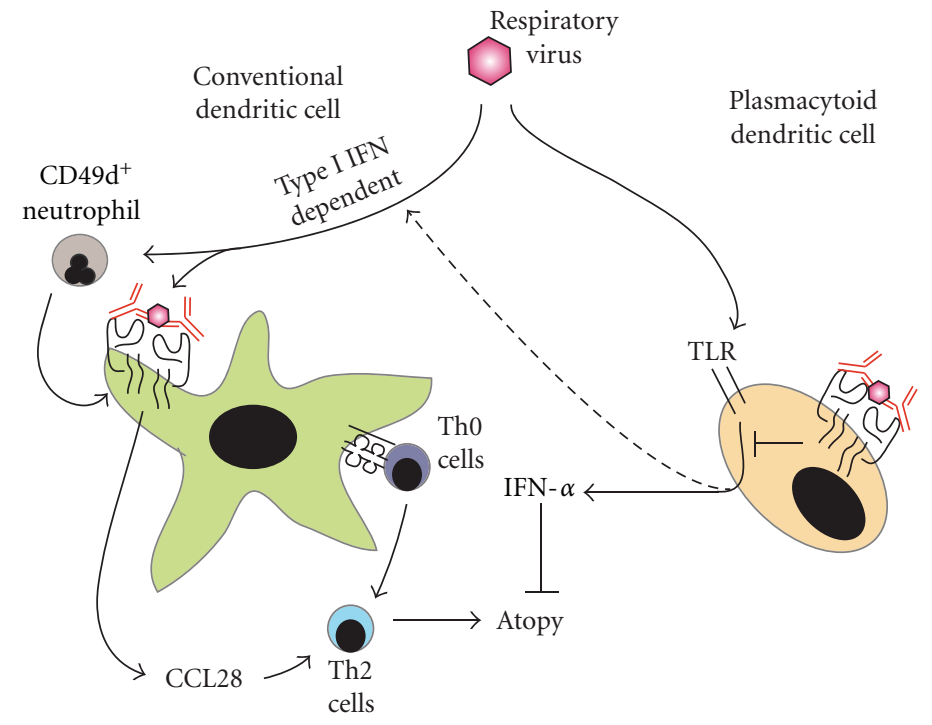

FIGURE 1: Proposed role of resident lung dendritic cells in the development of postviral atopic disease. After infection with a respiratory virus, both conventional (green cell) and plasmacytoid (tan cell) dendritic cells can influence the development of atopy. Conventional dendritic cells (cDCs) are able to present antigen to naïve T cells and skew their development towards a Th2 lineage (purple cell being converted to the blue cell). In addition, in a type I IFN-dependent fashion, CD49d-expressing neutrophils are recruited to the airway during the infection. These cells induce FceRI expression on lung cDC, which can be bound by anti-viral IgE. Subsequent cross-linking of the anti-viral IgE by virus leads to the production of CCL28, which further recruits Th2 cells to the airway, leading to atopic disease. The plasmacytoid dendritic cell (pDC) is induced to produce IFN- $\alpha$ by the viral infection through toll-like receptors (TLRs). The IFN- $\alpha$ blocks the development of atopy. Whether this type I IFN drives the CD49 $\mathrm{d}^{+}$neutrophil response is not known (the dotted line). Similar to the cDC, anti-viral IgE can bind FceRI on the pDC, with the free virus cross-linking the receptor. This impairs the release of IFN- $\alpha$ from the TLR removing the pDC-mediated inhibition of postviral atopic disease. See text for more details.

IFN- $\alpha$ production to control the infection and the fact that pDCs are a major cellular source of IFN- $\alpha$ during a viral infection. Therefore, a reduction in the ability to release IFN$\alpha$ could be a risk for developing atopic disease. In fact, studies of pDCs from peripheral blood and bronchoalveolar lavage (BAL) have documented that patients with allergic asthma have diminished influenza-induced and rhinovirus-induced IFN- $\alpha$ secretion, respectively, from pDCs when compared with healthy control subjects $[19,83]$. Tversky et al. [84] also found a similar impairment of IFN- $\alpha$ responses in pDCs from allergic subjects after stimulation with oligodeoxynucleotide-containing unmethylated CpG motifs (TLR9 agonist). Interestingly, there appears to be a counterbalance in human pDC when it comes to IgE- and TLR9-mediated IFN- $\alpha$ production. Cross-linking FceRI on human $\mathrm{pDC}$ was associated with reduced TLR9 expression and subsequent IFN- $\alpha$ production from a TLR9 agonist, while exposure to a TLR9 agonist first led to reduced expression of FceRI in the cells [85]. Furthermore, in an analysis of children from the COAST cohort, FceRI $\alpha$ expression on pDCs was inversely associated with hRV-induced IFN- $\alpha$ and IFN- $\lambda 1$ production [86]. The allergic asthmatic children in this study had higher surface expression of FceRI $\alpha$ on pDCs, and after FceRI cross-linking, they had significantly lower hRV-induced IFN responses than the allergic nonasthmatic children.

\section{Conclusion}

While the exact role viruses play in the overall development of asthma and atopic disease remains controversial, the data are compounding to suggest that resident lung $\mathrm{cDC}$ and pDC play a critical role in this process. Specifically, as shown in Figure 1, cDCs play a major role in both aeroallergen sensitization and in recruiting Th2 cells in an IgE-dependent fashion. These Th2 cells then lead to the development of postviral atopic disease with subsequent IgE production leading to spreading of allergic sensitization (something we have referred to as an "atopic cycle" [33]). Likely it is the combination of a reduced pDC IFN- $\alpha$ response in the presence of an activated cDC-FceRI-IgE-CCL2 8 axis that leads to the development of postviral atopic disease. Of course, it is also quite likely that an individual's genetic factors contribute to their overall response to the viral infection, further complicating studies exploring the risk of atopic disease and viral infection. Nonetheless, these studies have provided insights that will help to guide future therapeutic interventions to alter the pulmonary resident DC response and prevent the translation of viral into atopic disease. In fact, we hope it will not be long before infants who have severe viral infections will be treated with medications designed to block the development of postviral atopic disease. 


\section{Conflict of Interests}

J. S. Tam has no financial conflicts to disclose. M. H. Grayson has received research grants from the National Institutes of Health and Merck.

\section{Funding}

This work was funded by the NIH HL087778 (M. H. Grayson) and the Children's Research Institute of the Children's Hospital of Wisconsin (M. H. Grayson).

\section{References}

[1] M. I. Asher, S. Montefort, B. Björkstén et al., "Worldwide time trends in the prevalence of symptoms of asthma, allergic rhinoconjunctivitis, and eczema in childhood: ISAAC Phases One and Three repeat multicountry cross-sectional surveys," The Lancet, vol. 368, no. 9537, pp. 733-743, 2006.

[2] D. S. Cheung, S. J. Ehlenbach, T. Kitchens, D. A. Riley, and M. H. Grayson, "Development of atopy by severe paramyxoviral infection in a mouse model," Annals of Allergy, Asthma \& Immunology, vol. 105, no. 6, pp. 437.e1-443.e1, 2010.

[3] L. Perelmutter, P. Phipps, and L. Potvin, "Viral infections and IgE levels," Annals of Allergy, vol. 41, no. 3, pp. 158-159, 1978.

[4] L. Perelmutter, L. Potvin, and P. Phipps, "Immunoglobulin E response during viral infections," The Journal of Allergy and Clinical Immunology, vol. 64, no. 2, pp. 127-130, 1979.

[5] R. C. Welliver, T. N. Kaul, and P. L. Ogra, "The appearance of cell-bound IgE in respiratory-tract epithelium after respiratory-syncytial-virus infection," The New England Journal of Medicine, vol. 303, no. 21, pp. 1198-1202, 1980.

[6] R. C. Welliver, D. T. Wong, M. Sun et al., "The development of respiratory syncytial virus-specific IgE and the release of histamine in nasopharyngeal secretions after infection," The New England Journal of Medicine, vol. 305, no. 15, pp. 841-846, 1981.

[7] O. L. Frick, D. F. German, and J. Mills, "Development of allergy in children. I. Association with virus infections," The Journal of Allergy and Clinical Immunology, vol. 63, no. 4, pp. 228-241, 1979.

[8] N. Sigurs, R. Bjarnason, F. Sigurbergsson, B. Kjellman, and B. Björksten, "Asthma and immunoglobulin E antibodies after respiratory syncytial virus bronchiolitis: a prospective cohort study with matched controls," Pediatrics, vol. 95, no. 4, pp. 500-505, 1995.

[9] L. S. Subrata, J. Bizzintino, E. Mamessier et al., "Interactions between innate antiviral and atopic immunoinflammatory pathways precipitate and sustain asthma exacerbations in children," The Journal of Immunology, vol. 183, no. 4, pp. 27932800, 2009.

[10] F. D. Martinez, A. L. Wright, L. M. Taussig et al., "Asthma and wheezing in the first six years of life," The New England Journal of Medicine, vol. 332, no. 3, pp. 133-138, 1995.

[11] W. V. La Via, M. I. Marks, and H. R. Stutman, "Respiratory syncytial virus puzzle: clinical features, pathophysiology, treatment, and prevention," The Journal of Pediatrics, vol. 121, no. 4, pp. 503-510, 1992.

[12] H. C. Meissner, "Reducing the impact of viral respiratory infections in children," Pediatric Clinics of North America, vol. 52, no. 3, pp. 695-710, 2005.
[13] N. Sigurs, R. Bjarnason, F. Sigurbergsson, and B. Kjellman, "Respiratory syncytial virus bronchiolitis in infancy is an important risk factor for asthma and allergy at age 7," American Journal of Respiratory and Critical Care Medicine, vol. 161, no. 5, pp. 1501-1507, 2000.

[14] N. Sigurs, P. M. Gustafsson, R. Bjarnason et al., "Severe respiratory syncytial virus bronchiolitis in infancy and asthma and allergy at age 13," American Journal of Respiratory and Critical Care Medicine, vol. 171, no. 2, pp. 137-141, 2005.

[15] P. Wu, W. D. Dupont, M. R. Griffin et al., "Evidence of a causal role of winter virus infection during infancy in early childhood asthma," American Journal of Respiratory and Critical Care Medicine, vol. 178, no. 11, pp. 1123-1129, 2008.

[16] S. F. Thomsen, S. van der Sluis, L. G. Stensballe et al., "Exploring the association between severe respiratory syncytial virus infection and asthma: a registry-based twin study," American Journal of Respiratory and Critical Care Medicine, vol. 179, no. 12, pp. 1091-1097, 2009.

[17] A. Bufe, K. Gehlhar, E. Grage-Griebenow, and M. Ernst, "Atopic phenotype in children is associated with decreased virus-induced interferon- $\alpha$ release," International Archives of Allergy and Immunology, vol. 127, no. 1, pp. 82-88, 2002.

[18] K. Gehlhar, C. Bilitewski, K. Reinitz-Rademacher, G. Rohde, and A. Bufe, "Impaired virus-induced interferon- $\alpha 2$ release in adult asthmatic patients," Clinical and Experimental Allergy, vol. 36, no. 3, pp. 331-337, 2006.

[19] M. A. Gill, G. Bajwa, T. A. George et al., "Counterregulation between the FceRI pathway and antiviral responses in human plasmacytoid dendritic cells," The Journal of Immunology, vol. 184, no. 11, pp. 5999-6006, 2010.

[20] E. A. F. Simoes, J. R. Groothuis, X. Carbonell-Estrany et al., "Palivizumab prophylaxis, respiratory syncytial virus, and subsequent recurrent wheezing," The Journal of Pediatrics, vol. 151, no. 1, pp. 34.e1-42.e1, 2007.

[21] C.-H. Chen, Y.-T. Lin, Y.-H. Yang et al., "Ribavirin for re]spiratory syncytial virus bronchiolitis reduced the risk of asthma and allergen sensitization," Pediatric Allergy and Immunology, vol. 19, no. 2, pp. 166-172, 2008.

[22] R. T. Stein, D. Sherrill, W. J. Morgan et al., "Respiratory syncytial virus in early life and risk of wheeze and allergy by age 13 years," The Lancet, vol. 354, no. 9178, pp. 541-545, 1999.

[23] E. K. Miller, X. Lu, D. D. Erdman et al., "Rhinovirus-associated hospitalizations in young children," Journal of Infectious Diseases, vol. 195, no. 6, pp. 773-781, 2007.

[24] T. Jartti, P. Lehtinen, T. Vuorinen, and O. Ruuskanen, "Bronchiolitis: age and previous wheezing episodes are linked to viral etiology and atopic characteristics," The Pediatric Infectious Disease Journal, vol. 28, no. 4, pp. 311-317, 2009.

[25] D. J. Jackson, M. D. Evans, R. E. Gangnon, C. J. Tisler, T. E. Pappas, W.-M. Lee et al., "Evidence for a causal relationship between allergic sensitization and rhinovirus wheezing in early life," American Journal of Respiratory and Critical Care Medicine, vol. 185, no. 3, pp. 281-285, 2012.

[26] A. Kotaniemi-Syrjänen, R. Vainionpää, T. M. Reijonen, M. Waris, K. Korhonen, and M. Korppi, "Rhinovirus-induced wheezing in infancy - the first sign of childhood asthma?" The Journal of Allergy and Clinical Immunology, vol. 111, no. 1, pp. 66-71, 2003.

[27] K. N. Carroll, P. Wu, T. Gebretsadik et al., "Season of infant bronchiolitis and estimates of subsequent risk and burden of early childhood asthma," The Journal of Allergy and Clinical Immunology, vol. 123, no. 4, pp. 964-966, 2009. 
[28] R. F. Lemanske, "The childhood origins of asthma (COAST) study," Pediatric Allergy and Immunology, vol. 13, supplement 15, pp. 38-43, 2002.

[29] R. F. Lemanske, D. J. Jackson, R. E. Gangnon et al., "Rhinovirus illnesses during infancy predict subsequent childhood wheezing," The Journal of Allergy and Clinical Immunology, vol. 116, no. 3, pp. 571-577, 2005.

[30] D. J. Jackson, R. E. Gangnon, M. D. Evans et al., "Wheezing rhinovirus illnesses in early life predict asthma development in high-risk children," American Journal of Respiratory and Critical Care Medicine, vol. 178, no. 7, pp. 667-672, 2008.

[31] S. L. Friedlander, D. J. Jackson, R. E. Gangnon et al., "Viral infections, cytokine dysregulation and the origins of childhood asthma and allergic diseases," The Pediatric Infectious Disease Journal, vol. 24, no. 11, pp. S170-S176, 2005.

[32] M. M. H. Kusel, N. H. de Klerk, T. Kebadze et al., "Earlylife respiratory viral infections, atopic sensitization, and risk of subsequent development of persistent asthma," The Journal of Allergy and Clinical Immunology, vol. 119, no. 5, pp. 11051110, 2007.

[33] A. Kumar and M. H. Grayson, "The role of viruses in the development and exacerbation of atopic disease," Annals of Allergy, Asthma \& Immunology, vol. 103, no. 3, pp. 181-187, 2009.

[34] D. Cheung and M. Grayson, "Role of viruses in the development of atopic disease in pediatricpatients," Current Allergy and Asthma Reports. In press.

[35] M. Colonna, G. Trinchieri, and Y.-J. Liu, "Plasmacytoid dendritic cells in immunity," Nature Immunology, vol. 5, no. 12, pp. 1219-1226, 2004.

[36] W. Barchet, A. Blasius, M. Cella, and M. Colonna, "Plasmacytoid dendritic cells: in search of their niche in immune responses," Immunologic Research, vol. 32, no. 1-3, pp. 75-83, 2005.

[37] M. Salio, M. J. Palmowski, A. Atzberger, I. F. Hermans, and V. Cerundolo, "CpG-matured murine plasmacytoid dendritic cells are capable of in vivo priming of functional CD8 T cell responses to endogenous but not exogenous antigens," The Journal of Experimental Medicine, vol. 199, no. 4, pp. 567-579, 2004.

[38] J. C. Ochando, C. Homma, Y. Yang et al., "Alloantigen-presenting plasmacytoid dendritic cells mediate tolerance to vascularized grafts," Nature Immunology, vol. 7, no. 6, pp. 652-662, 2006.

[39] M. Gilliet, W. Cao, and Y.-J. Liu, "Plasmacytoid dendritic cells: sensing nucleic acids in viral infection and autoimmune diseases," Nature Reviews Immunology, vol. 8, no. 8, pp. 594-606, 2008.

[40] M. Irla, N. Küpfer, T. Suter et al., "MHC class II-restricted antigen presentation by plasmacytoid dendritic cells inhibits $\mathrm{T}$ cell-mediated autoimmunity," The Journal of Experimental Medicine, vol. 207, no. 9, pp. 1891-1905, 2010.

[41] H. Takagi, T. Fukaya, K. Eizumi, Y. Sato, K. Sato, A. Shibazaki et al., "Plasmacytoid dendritic cells are crucial for the initiation of inflammation and T cell immunity in vivo," Immunity, vol. 35, no. 6, pp. 958-971, 2011.

[42] S. Hanabuchi and Y.-J Liu, "In vivo role of pDCs in regulating adaptive immunity," Immunity, vol. 35, no. 6, pp. 851-853, 2011.

[43] M. M. Meredith, K. Liu, G. Darrasse-Jeze, A. O. Kamphorst, H. A. Schreiber, P. Guermonprez et al., "Expression of the zinc finger transcription factor $\mathrm{zDC}$ (Zbtb46, Btbd4) defines the classical dendritic cell lineage," The Journal of Experimental Medicine, vol. 209, no. 6, pp. 1153-1165, 2012.
[44] A. T. Satpathy, K. C. Wumesh, J. C. Albring, B. T. Edelson, N. M. Kretzer, D. Bhattacharya et al., "Zbtb46 expression distinguishes classical dendritic cells and their committed progenitors from other immune lineages," The Journal of Experimental Medicine, vol. 209, no. 6, pp. 1135-1152, 2012.

[45] T. V. Condon, R. T. Sawyer, M. J. Fenton, and D. W. H. Riches, "Lung dendritic cells at the innate-adaptive immune interface," Journal of Leukocyte Biology, vol. 90, no. 5, pp. 883-895, 2011.

[46] L. S. van Rijt, S. Jung, A. KleinJan et al., "In vivo depletion of lung $\mathrm{CD}_{11 \mathrm{c}^{+}}$dendritic cells during allergen challenge abrogates the characteristic features of asthma," The Journal of Experimental Medicine, vol. 201, no. 6, pp. 981-991, 2005.

[47] S.-S. J. Sung, S. M. Fu, C. E. Rose, F. Gaskin, S.-T. Ju, and S. R. Beaty, "A major lung CD103 $(\alpha \mathrm{E})-\beta 7$ integrin-positive epithelial dendritic cell population expressing langerin and tight junction proteins," The Journal of Immunology, vol. 176, no. 4, pp. 2161-2172, 2006.

[48] B. D. Medoff, E. Seung, S. Hong et al., "CD11b ${ }^{+}$myeloid cells are the key mediators of Th2 cell homing into the airway in allergic inflammation," The Journal of Immunology, vol. 182, no. 1, pp. 623-635, 2009.

[49] B. L. Kelsall, C. A. Biron, O. Sharma, and P. M. Kaye, "Dendritic cells at the host-pathogen interface," Nature Immunology, vol. 3, no. 8, pp. 699-702, 2002.

[50] K. Sertl, T. Takemura, E. Tschachler et al., "Dendritic cells with antigen-presenting capability reside in airway epithelium, lung parenchyma, and visceral pleura," The Journal of Experimental Medicine, vol. 163, no. 2, pp. 436-451, 1986.

[51] A. S. McWilliam, D. J. Nelson, and P. G. Holt, "The biology of airway dendritic cells," Immunology and Cell Biology, vol. 73, no. 5, pp. 405-413, 1995.

[52] B. N. Lambrecht, B. Salomon, D. Klatzmann, and R. A. Pauwels, "Dendritic cells are required for the development of chronic eosinophilic airway inflammation in response to inhaled antigen in sensitized mice," The Journal of Immunology, vol. 160, no. 8, pp. 4090-4097, 1998.

[53] P. G. Holt, "Pulmonary dendritic cells in local immunity to inert and pathogenic antigens in the respiratory tract," Proceedings of the American Thoracic Society, vol. 2, no. 2, pp. 116$120,2005$.

[54] P. A. Stumbles, D. H. Strickland, C. L. Pimm et al., "Regulation of dendritic cell recruitment into resting and inflamed airway epithelium: use of alternative chemokine receptors as a function of inducing stimulus," The Journal of Immunology, vol. 167, no. 1, pp. 228-234, 2001.

[55] P. G. Holt, S. Haining, D. J. Nelson, and J. D. Sedgwick, “Origin and steady-state turnover of class II MHC-bearing dendritic cells in the epithelium of the conducting airways," The Journal of Immunology, vol. 153, no. 1, pp. 256-261, 1994.

[56] M. Ghaznawie, J. M. Papadimitriou, and P. J. Heenan, "The steady-state turnover of murine epidermal Langerhans cells," British Journal of Dermatology, vol. 141, no. 1, pp. 57-61, 1999.

[57] I. Fugier-Vivier, C. Servet-Delprat, P. Rivailler, M.-C. Rissoan, Y.-J. Liu, and C. Rabourdin-Combe, "Measles virus suppresses cell-mediated immunity by interfering with the survival and functions of dendritic and T cells," The Journal of Experimental Medicine, vol. 186, no. 6, pp. 813-823, 1997.

[58] J. Engelmayer, M. Larsson, M. Subklewe et al., "Vaccinia virus inhibits the maturation of human dendritic cells: a novel mechanism of immune evasion," The Journal of Immunology, vol. 163 , no. 12 , pp. 6762-6768, 1999. 
[59] M. Salio, M. Cella, M. Suter, and A. Lanzavecchia, "Inhibition of dendritic cell maturation by herpes simplex virus," European Journal of Immunology, vol. 29, no. 10, pp. 3245-3253, 1999.

[60] D. Tortorella, B. E. Gewurz, M. H. Furman, D. J. Schust, and H. L. Ploegh, "Viral subversion of the immune system," Annual Review of Immunology, vol. 18, no. 1, pp. 861-926, 2000.

[61] A. Cambi, F. de Lange, N. M. van Maarseveen et al., "Microdomains of the C-type lectin DC-SIGN are portals for virus entry into dendritic cells," The Journal of Cell Biology, vol. 164, no. 1, pp. 145-155, 2004.

[62] J. F. Fonteneau, D. G. Kavanagh, M. Lirvall et al., "Characterization of the MHC class I cross-presentation pathway for cellassociated antigens by human dendritic cells," Blood, vol. 102, no. 13, pp. 4448-4455, 2003.

[63] P. S. Ohashi and A. L. DeFranco, "Making and breaking tolerance," Current Opinion in Immunology, vol. 14, no. 6, pp. 744759, 2002.

[64] C. J. M. Melief, "Mini-review: regulation of cytotoxic T lymphocyte responses by dendritic cells: peaceful coexistence of cross-priming and direct priming?" European Journal of Immunology, vol. 33, no. 10, pp. 2645-2654, 2003.

[65] K. L. Legge and T. J. Braciale, "Accelerated migration of respiratory dendritic cells to the regional lymph nodes is limited to the early phase of pulmonary infection," Immunity, vol. 18, no. 2, pp. 265-277, 2003.

[66] M. H. Grayson, M. S. Ramos, M. M. Rohlfing et al., "Controls for lung dendritic cell maturation and migration during respiratory viral infection," The Journal of Immunology, vol. 179, no. 3, pp. 1438-1448, 2007.

[67] M. A. Gill, K. Long, T. Kwon et al., "Differential recruitment of dendritic cells and monocytes to respiratory mucosal sites in children with influenza virus or respiratory syncytial virus infection," Journal of Infectious Diseases, vol. 198, no. 11, pp. 1667-1676, 2008.

[68] C. Asselin-Paturel, G. Brizard, J.-J. Pin, F. Brière, and G. Trinchieri, "Mouse Strain Differences in Plasmacytoid Dendritic Cell Frequency and Function Revealed by a Novel Monoclonal Antibody," The Journal of Immunology, vol. 171, no. 12, pp. 6466-6477, 2003.

[69] H. Wang, N. Peters, V. Laza-Stanca, N. Nawroly, S. L. Johnston, and J. Schwarze, "Local CD11 $c^{+}$MHC class II-precursors generate lung dendritic cells during respiratory viral infection, but are depleted in the process," The Journal of Immunology, vol. 177, no. 4, pp. 2536-2542, 2006.

[70] A. L. Pritchard, M. L. Carroll, J. G. Burel, O. J. White, S. Phipps, and J. W. Upham, "Innate IFNs and plasmacytoid dendritic cells constrain Th2 cytokine responses to rhinovirus: a regulatory mechanism with relevance to asthma," The Journal of Immunology, vol. 188, no. 12, pp. 5898-5905, 2012.

[71] M. Sakamoto, S. Ida, and T. Takishima, "Effect of influenza virus infection on allergic sensitization to aerosolized ovalbumin in mice," The Journal of Immunology, vol. 132, no. 5, pp. 2614-2617, 1984.

[72] S. Suzuki, Y. Suzuki, N. Yamamoto, Y. Matsumoto, A. Shirai, and T. Okubo, "Influenza A virus infection increases IgE production and airway responsiveness in aerosolized antigenexposed mice," The Journal of Allergy and Clinical Immunology, vol. 102, no. 5, pp. 732-740, 1998.

[73] N. Yamamoto, S. Suzuki, A. Shirai, M. Suzuki, M. Nakazawa, Y. Nagashima et al., "Dendritic cells are associated with augmentation of antigen sensitization by influenza A virus infection in mice," European Journal of Immunology, vol. 30, no. 1, pp. 316-326, 2000.
[74] J. Freihorst, P. A. Piedra, Y. Okamoto, and P. L. Ogra, "Effect of respiratory syncytial virus infection on the uptake of and immune response to other inhaled antigens," Proceedings of the Society for Experimental Biology and Medicine, vol. 188, no. 2, pp. 191-197, 1988.

[75] E. Leibovitz, J. Freihorst, P. A. Piedra, and P. L. Ogra, "Modulation of systemic and mucosal immune responses to inhaled ragweed antigen in experimentally induced infection with respiratory syncytial virus implication in virally induced allergy," International Archives of Allergy and Applied Immunology, vol. 86, no. 1, pp. 112-116, 1988.

[76] M. J. Walter, J. D. Morton, N. Kajiwara, E. Agapov, and M. J. Holtzman, "Viral induction of a chronic asthma phenotype and genetic segregation from the acute response," The Journal of Clinical Investigation, vol. 110, no. 2, pp. 165-175, 2002.

[77] D. S. Cheung, S. J. Ehlenbach, R. T. Kitchens et al., "Cutting edge: $\mathrm{CD}_{4} 9 \mathrm{~d}^{+}$neutrophils induce FceRI expression on lung dendritic cells in a mouse model of postviral asthma," The Journal of Immunology, vol. 185, no. 9, pp. 4983-4987, 2010.

[78] M. H. Grayson, D. Cheung, M. M. Rohlfing et al., "Induction of high-affinity IgE receptor on lung dendritic cells during viral infection leads to mucous cell metaplasia," The Journal of Experimental Medicine, vol. 204, no. 11, pp. 2759-2769, 2007.

[79] R. Stephens and D. D. Chaplin, "IgE cross-linking or lipopolysaccharide treatment induces recruitment of Th2 cells to the lung in the absence of specific antigen," The Journal of Immunology, vol. 169, no. 10, pp. 5468-5476, 2002.

[80] S. H. Khan and M. H. Grayson, "Cross-linking IgE augments human conventional dendritic cell production of CC chemokine ligand 28," The Journal of Allergy and Clinical Immunology, vol. 125, no. 1-3, pp. 265-267, 2010.

[81] M. Vasudev, D. S. Cheung, H. Pincsak, S.-H. Li, K. Yan, P. Simpson et al., "Expression of high-affinity IgE receptor on human peripheral blood dendritic cells in children," PLoS ONE, vol. 7, no. 2, Article ID e32556, 2012.

[82] J. J. Smit, B. D. Rudd, and N. W. Lukacs, "Plasmacytoid dendritic cells inhibit pulmonary immunopathology and promote clearance of respiratory syncytial virus," The Journal of Experimental Medicine, vol. 203, no. 5, pp. 1153-1159, 2006.

[83] A. Sykes, M. R. Edwards, J. Macintyre, A. del Rosario, E. Bakhsoliani, M.-B. Trujillo-Torralbo et al., "Rhinovirus 16induced IFN- $\alpha$ and IFN- $\beta$ are deficient in bronchoalveolar lavage cells in asthmatic patients," The Journal of Allergy and Clinical Immunology, vol. 129, no. 6, pp. 1506.e6-1514.e6, 2012.

[84] J. R. Tversky, T. V. Le, A. P. Bieneman, K. L. Chichester, R. G. Hamilton, and J. T. Schroeder, "Human blood dendritic cells from allergic subjects have impaired capacity to produce interferon- $\alpha$ via toll-like receptor 9," Clinical and Experimental Allergy, vol. 38, no. 5, pp. 781-788, 2008.

[85] J. T. Schroeder, A. P. Bieneman, H. Xiao et al., "TLR9- and FceRI-mediated responses oppose one another in plasmacytoid dendritic cells by down-regulating receptor expression," The Journal of Immunology, vol. 175, no. 9, pp. 5724-5731, 2005.

[86] S. R. Durrani, D. J. Montville, A. S. Pratt, S. Sahu, M. K. DeVries, V. Rajamanickam et al., "Innate immune responses to rhinovirus are reduced by the high-affinity IgE receptor in allergic asthmatic children," The Journal of Allergy and Clinical Immunology, vol. 130, no. 2, pp. 489-495, 2012. 


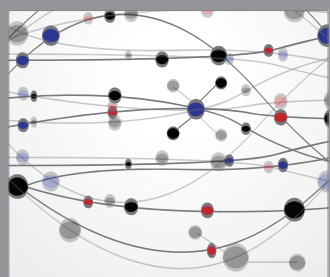

The Scientific World Journal
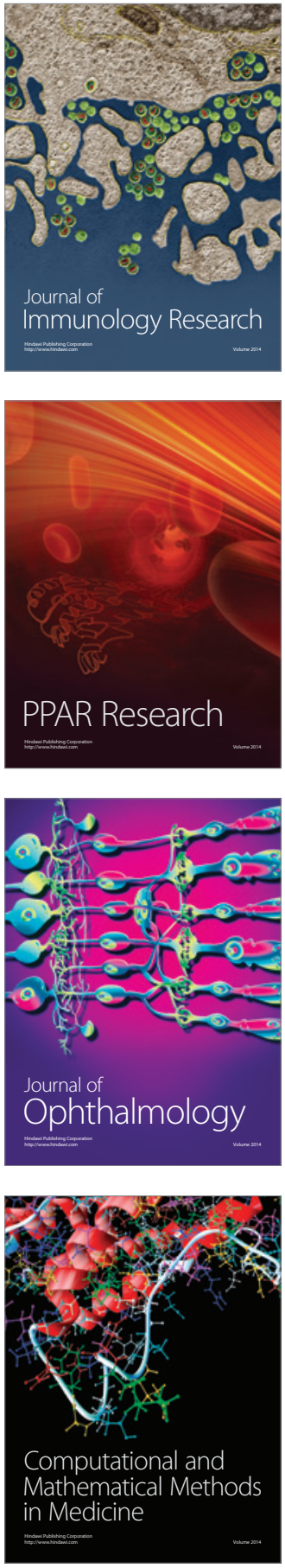

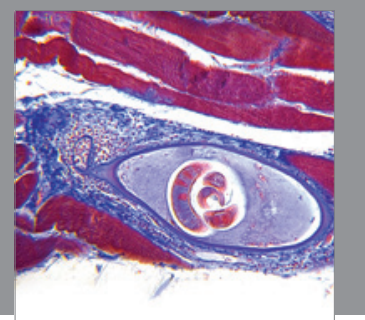

Gastroenterology

Research and Practice
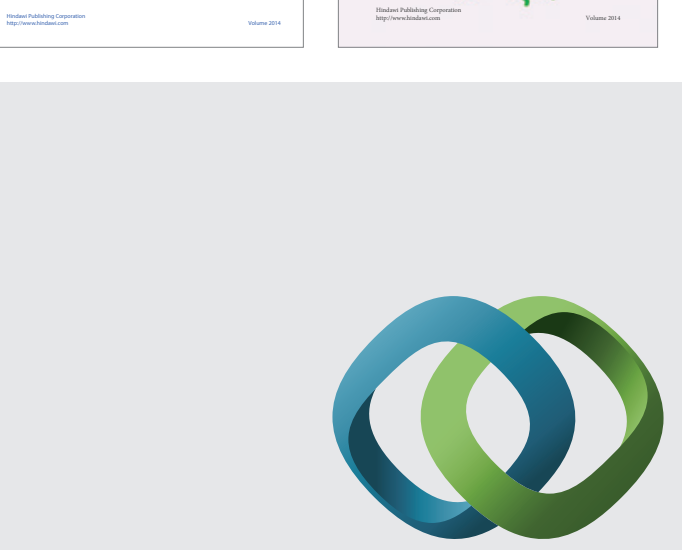

\section{Hindawi}

Submit your manuscripts at

http://www.hindawi.com
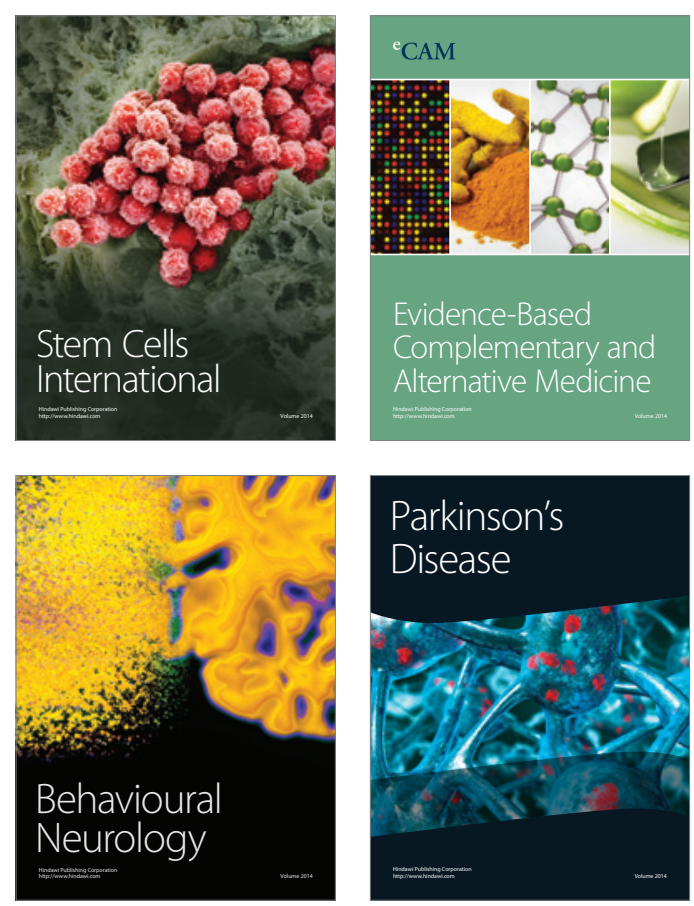

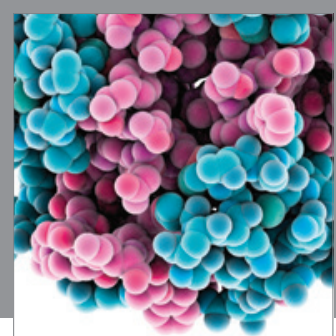

Journal of
Diabetes Research

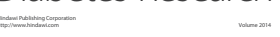

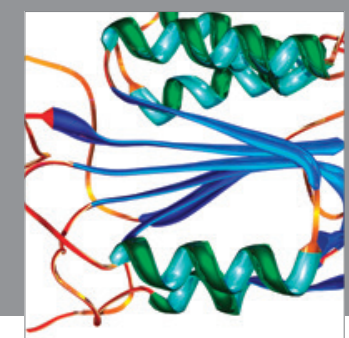

Disease Markers
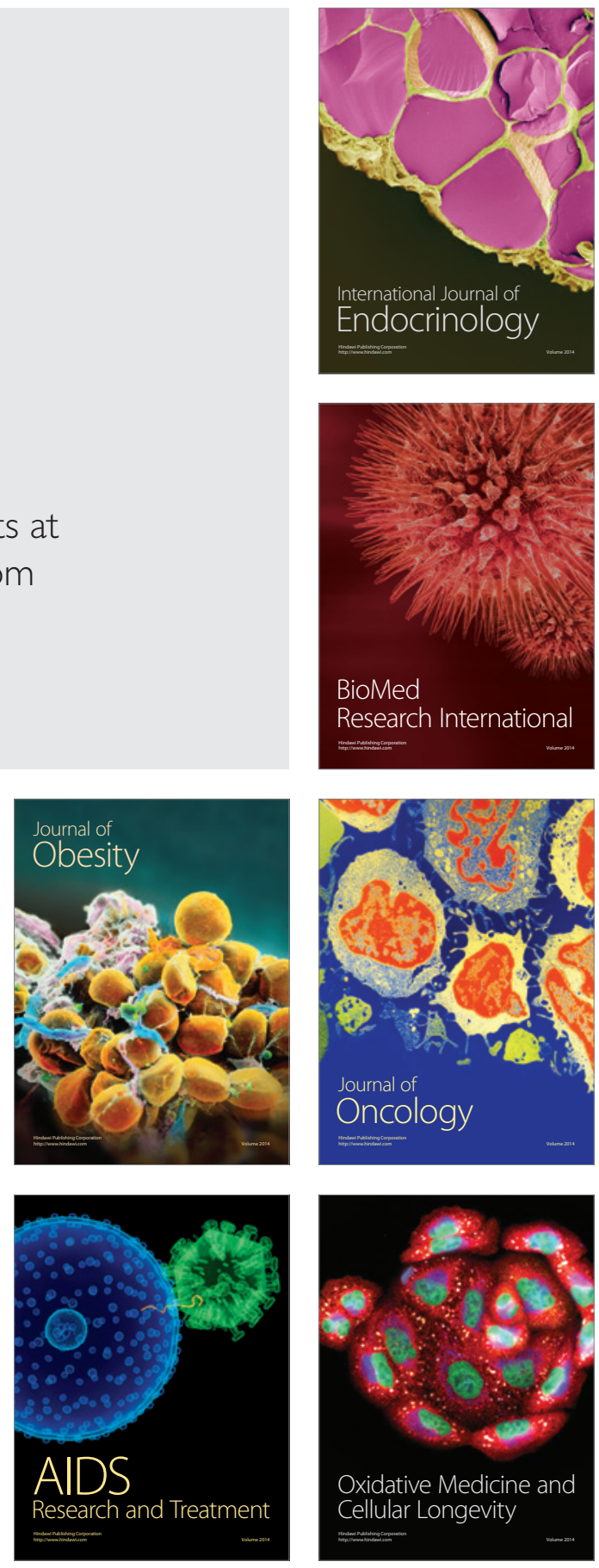